\title{
A compulsão alimentar como objeto de pesquisa da Antropologia das Emoções
}

Bianca Sophia ${ }^{1}$

\section{Resumo}

Segundo a literatura médica, a compulsão alimentar periódica é uma categoria relativamente recente (1994), se comparada com a anorexia (criada na década de 1970) e a bulimia (estabelecida por volta de 1980). Tal comportamento se caracteriza por episódios recorrentes de compulsão alimentar sem métodos compensatórios (uso de laxantes, de diuréticos, de exercícios físicos etc.). Diferentemente dos outros transtornos alimentares, cujo desejo de emagrecer é preponderante, a compulsão alimentar está relacionada a episódios recorrentes de ingestão de grande quantidade de comida e a sentimentos acentuados de culpa e de angústia. Ao investigar os fatores sociais e culturais da compulsão alimentar, este trabalho utiliza como ponto de partida o modo como o discurso biomédico ganha destaque na contemporaneidade ao ditar padrões de comportamento e formatos corporais "saudáveis", aliados às questões sobre a aparência física e o consumismo.

Palavras-chave: Compulsão alimentar. Contemporaneidade. Antropologia das Emoções. Saúde

\begin{abstract}
According to medical literature, binge eating disorder is a relatively new category (1994), compared to anorexia (created in 1970) and bulimia (established around 1980). Such behavior is characterized by recurrent episodes of binge eating without compensatory methods (use of laxatives, diuretics, exercise etc.). Unlike other eating disorders, whose desire to lose weight is preponderant, binge eating is related to recurrent episodes of eating large amount of food and the enhanced feelings of guilt and anguish. To investigate the social and cultural factors of binge eating disorder, this work uses as a starting point how the biomedical discourse gained prominence in the

\footnotetext{
${ }^{1}$ Doutoranda no Programa de Pós-Graduação em Ciências Sociais (PPCIS) da Universidade do Estado do Rio de Janeiro (UERJ), com bolsa da Fundação Carlos Chagas de Amparo à Pesquisa do Estado do Rio de Janeiro (FAPERJ). E-mail: bvsophia@gmail.com
} 
contemporary to dictate behavior patterns and body shapes "healthy", combined with questions about the physical appearance and consumerism.

Keywords: Binge eating disorder. Contemporaneity. Anthropology of Emotions. Health

Recebido em: Julho, 2015

Aceito em: Outubro, 2015

Para citar este artigo:

SOPHIA, Bianca. "A compulsão alimentar como objeto de pesquisa da Antropologia das Emoções".In: Revista Intratextos, 2015, vol 6, no1, p. 85-108. DOI: http://dx.doi.org/10.12957/intratextos.2015.17499 


\section{Introdução}

O presente artigo faz uma breve revisão de literatura acerca dos fatores sociais que envolvem os transtornos alimentares, em especial a compulsão alimentar, com o intuito de levantar alguns pontos sobre como determinadas configurações socioculturais podem influenciar os estados de saúde/doença e os estilos de vida dos indivíduos. Considera-se, de modo geral, que as diferentes formas de lidar com as manifestações orgânicas, emocionais ou comportamentais, classificadas pelo campo biomédico como doenças, são importantes para a elaboração de reflexões a respeito da constituição de identidades e de grupos de indivíduos que compartilham essas experiências. No caso dos transtornos alimentares, tais experiências são perpassadas por representações que nem sempre partilham das mesmas concepções ditadas pelos manuais de diagnóstico psiquiátrico (LIRA, 2006; SACCOL, 2009; SOPHIA, 2009; $2011)^{2}$.

Apesar do viés identitário apontado pelo assunto, o foco desse trabalho é a articulação das noções abordadas pelos manuais psiquiátricos acerca da compulsão alimentar ${ }^{3}$ às questões tratadas pelo campo da Antropologia das Emoções de modo a contribuir para análise desse fenômeno. As emoções, nesse sentido, são discutidas aqui não como atributos universais característicos de uma unidade biológica ou psíquica dos indivíduos, mas como um conjunto de diversas experiências corporais e psicológicas mediadas pelas transformações históricas e culturais (REZENDE, COELHO, 2010). É na interação dos indivíduos que os "padrões emocionais" de uma determinada cultura são assimilados. Imersos nessa dinâmica, os sujeitos aprendem a gerenciar suas emoções conforme as situações cotidianas (festas, vida familiar e profissional, enterros etc.). O problema surge quando esses sujeitos não conseguem se adequar às "convenções sentimentais" (HOCHSCHILD, 2013) e às expectativas sociais em relação aos comportamentos alimentares, corporais, de saúde etc. Esse é o fio que conduz a investigação sobre a compulsão alimentar.

\footnotetext{
${ }^{2}$ Refiro-me aqui aos grupos pró-anorexia e pró-bulimia da internet que ressignificam essas categorias em defesa de um "estilo magro de ser" (LIRA, 2006; SOPHIA, 2009; 2011); e à irmandade dos Comedores Compulsivos Anônimos (CCA). Nesses casos, a autoidentificação com determinado transtorno é mais recorrente do que o diagnóstico médico. O estudo de Saccol (2009) é outro exemplo de formas de representação dos transtornos alimentares, pois demonstra que até para os profissionais de saúde essa doença pode ganhar novos sentidos e significados, dependendo da área de atuação (Nutrição, Enfermagem, Psiquiatria etc.).

3 O principal manual psiquiátrico é o Manual Diagnóstico e Estatístico de Transtornos Mentais, tradução em português para o Diagnostic and Statistical Manual of Mental Disorders, V Edition (DSM-V).
} 
Os simbolismos atrelados à comida e a outros fenômenos, como a moda, o consumismo e o processo de medicalização das sociedades ocidentais, são apresentados nas próximas seções na tentativa de problematizar como tais elementos dialogam com a formulação do transtorno da compulsão alimentar periódica (TCAP) pela biomedicina e seus reflexos nas experiências físicas e subjetivas dos indivíduos. A figura do compulsivo começa a ser delineada na Idade Média, com a Igreja Católica, mas adquire status de patologia subjetiva com as transformações ocorridas no mundo moderno. Pecado, doença e vício são descritos como algumas das representações sociais atribuídas a esse comportamento.

\section{A comida: necessidade ou pecado?}

Comer é o ato mais comum entre os indivíduos e também o mais singular e egoísta de todos, pois o que se come pode não ser consumido por outros. Essa ideia, defendida por Georg Simmel em seu ensaio Sociologia da refeição (1910), pretende demonstrar como um ato tão simples e universal, como o de ingerir determinado alimento, é um mecanismo socializador e distintivo, que assume formas estilizadas, estéticas e regulares dentro dos grupos sociais.

O que está em jogo, para o autor, não são apenas a comida como matéria e as necessidades de saciar-se, mas também um conjunto de relações envolvidas que ditam os diversos modos de se comportar à mesa. Isso nos leva a crer que, além de ser uma necessidade orgânica, a comida está diretamente atrelada à nossa identidade social e a nós mesmos (MINTZ, 2001).

Ao falarmos da compulsão por alimentos devemos ter em mente a questão do papel dado à comida e, principalmente, ao comportamento alimentar em nossa sociedade para compreendermos como esse fator se articula aos discursos sobre saúde e doença na contemporaneidade. Para Francine Prose (2004), nossa fixação pela saúde e o nosso fascínio pela doença e pela morte depositam falsas esperanças de que as dietas e os exercícios físicos possibilitem uma vida eterna. Tal visão "demoniza" o ato de comer, especialmente se o indivíduo comer em excesso.

A obsessão pela comida e pelas dietas refletem uma briga entre os polos relacionados ao pecado/virtude, ao descontrole alimentar/autocontrole e à saúde/doença, que representam um modo contemporâneo de observação da natureza da gula como tentação nas sociedades ocidentais. Segundo a autora: 
Traçar a evolução [da gula] é refletir sobre o lugar de onde viemos, aonde chegamos e para onde podemos estar indo. Porque se, como dizem, nós somos o que comemos, então o que sentimos sobre comida - e o comer demais - revela nossas mais profundas crenças sobre quem somos, quem nos tornaremos e as relações e conflitos entre as necessidades do corpo e os desejos do espírito [e as expectativas sociais] (PROSE, 2004, p.14).

$\mathrm{O}$ ato de comer demasiadamente é descrito ao longo da história de maneira intrigante e paradoxal. Na tradição greco-romana, os banquetes eram vistos como eventos de contato social e estabelecimento de alianças entre grupos. No entanto, os filósofos da época, como Aristóteles, Plutarco, entre outros, defendiam o comportamento equilibrado e o uso parcimonioso da comida e da bebida em nome da preservação da vida.

A gula, de acordo com Prose, torna-se pecado na Idade Média, pois representava o culto aos sentidos e a contaminação. No primeiro caso, a gula ${ }^{4}$ levaria ao afastamento da atenção a Deus e, no segundo, ao enfraquecimento moral que abre caminho para libertinagem, devassidão e outros pecados, como a ira e a preguiça. A gula era vista como "um mal de algo pior", que constantemente era mencionado nos textos bíblicos e propagado pelos primeiros teólogos católicos.

Os jejuns e as comilanças conviviam de forma contraditória em um período em que a ideia de ida ao inferno não era uma metáfora, mas uma realidade para os bons cristãos. O medo e a culpa eram especiarias que temperavam a refeição do glutão e ainda persistem em deixar marcas (PROSE, 2004).

Ao final do século XX, a comida, por um lado, passou a significar compensação, conforto ou um meio de liberação do sofrimento (ROTH, 1991 apud PROSE, 2004), por outro, algo que desencadeia sentimentos de culpa e de perda de controle que levam a problemas de saúde e a disfunções alimentares. Assim, as pessoas que não estão conforme as normas corporais estabelecidas por nossa cultura são submetidas a diferentes doses de insulto, de humilhação, de preconceito e de discriminação. A gula, nesse sentido, passou de uma lista pessoal de falhas de caráter e de crime contra a ordem divina para o mais torturante dos pecados públicos, pois, agora, o glutão não precisa temer uma vida punitiva após a morte, mas a morte em si - a morte prematura ocasionada pelos excessos alimentares.

\footnotetext{
${ }^{4}$ Nesse período a gula também estava relacionada à bebedeira.
} 


\section{Os irmãos do pecado: a moda, o consumismo e a medicalização da vida}

Georg Simmel (1998) também escreveu sobre os fenômenos relacionados à moda e suas contradições. Para o autor: "A moda é uma forma peculiar dentre aquelas formas de vida, por meio das quais se procura produzir um compromisso entre a tendência para a igualdade social e a tendência para marcar a distinção individual" (SIMMEL, 1998, p. 161). A moda é o meio no qual os indivíduos têm de adquirir prestígio, satisfação e de se assemelhar à multidão. Sua essência está na ideia de que apenas uma parcela da sociedade pode ter acesso a ela. Não por acaso, a noção de que a moda "nunca é, mas é sempre um vir a ser" (SIMMEL, 1998, p. 162). Quando a moda passa a ser dominante, outras modas aparecem. Isso explica não apenas as transformações comportamentais (dos modos de se vestir, dos usos de acessórios, de personalidades etc.), mas também destaca uma relação desigual entre os grupos de indivíduos com mais e menos prestígio social.

$\mathrm{Na}$ tentativa de pontuar alguns dos elementos que fazem parte da dinâmica atrelada às discussões sobre os transtornos alimentares, menciono novamente a reflexão de Simmel sobre a moda por considerá-la muito fecunda para o desenvolvimento da argumentação acerca da supervalorização da aparência física e do estabelecimento de um estilo de vida "saudável" como aspectos cada vez mais frequentes do comportamento individual. Atualmente, "estar na moda" é, em nossa cultura, ter um corpo que personifique a beleza, ou seja, um corpo isento de gordura (seja magro ou musculoso) e de outras substâncias consideradas nocivas à saúde (o açúcar e o sal, por exemplo). Entretanto, nem todos têm acesso a bens e a serviços de saúde e de estética ou, simplesmente, têm uma estrutura física que possa estar conforme aos tipos ideais de formato corporal. Os sujeitos que não conseguem acampanhar os ditames desse modismo sofrem com diversos mecanismos de pressão social.

Somos expostos às inúmeras informações veiculadas na mídia que apresentam dietas milagrosas, exercícios físicos, fórmulas antienvelhecimento, cirurgias plásticas, entre outras técnicas. Existe um aparato tecnológico a serviço da estética e da saúde que busca imprimir nos corpos um formato ideal que hierarquiza e qualifica os sujeitos (SUDO, 2004). Estamos imersos em uma "cultura consumista", responsável pela configuração das relações sociais pautadas 
pelos mercados de bens e de consumo, em que as marcas identitárias transformam-se em produtos de um "marketing pessoal" (BAUMAN, 2008).

Segundo essa perspectiva, vivemos em um período de "encurtamento" radical da expectativa de vida do desejo humano que se acelera com sua satisfação e o estabelecimento de outros objetos de desejo. Isso seria apontado como fruto de uma "síndrome consumista" que "envolve velocidade, excesso e desperdício" (BAUMAN, 2008, p. 111). O ato de se livrar de coisas que "passaram da validade" significa a oportunidade de novos prazeres, estímulos ou desejos, ainda que gerem neste homem contemporâneo um constante sentimento de insatisfação.

No que diz respeito à aparência física, a insatisfação com o formato corporal faz com que os sujeitos recorram a diversas técnicas estéticas, exercícios ou condutas ascéticas em prol de saciar o desejo de estar apto ao mercado consumidor. Contudo, do mesmo modo que existe a insatisfação, há ainda o sentimento de insuficiência (COELHO; SEVERIANO, 1998) que emana da sensação de incapacidade de se fazer frente ao excesso de possibilidades e exigências prescritas pela sociedade de consumo. $\mathrm{O}$ resultado desse processo é a verdadeira angústia neurótica e o sofrimento vivenciado pelos indivíduos em meio às constantes mudanças impulsionadas na contemporaneidade. Nesse contexto, o aparecimento de perturbações, como a anorexia, a bulimia e a compulsão alimentar, representam a tensão entre a pluralidade de opções oferecidas e a exclusão do indivíduo de determinadas condições.

A questão da medicalização da vida também faz parte desse cenário. Estamos em uma época em que o discurso médico ocupa um lugar de destaque na sociedade Ocidental e atua na produção de comportamentos que são definidos e avaliados em termos de saúde/normalidade e doença. Mas nem sempre foi assim. Esse status médico foi constituído ao longo de vários séculos, principalmente no período que inaugura a medicina moderna.

Para Michel Foucault $(1980 ; 1996)$, os pressupostos da medicina moderna são produzidos por transformações nos procedimentos do saber. De acordo com essa concepção, a relação de conhecimento entre o sujeito e o objeto em nome do saber se instaura na infraestrutura dessas sociedades, passando, então, a serem mecanismos do poder. Há também uma configuração da linguagem, da relação de situação e de postura entre "o que se fala" e "aquilo de que se fala". A linguagem, em um momento anterior a essas transformações, não separava as coisas e as palavras, "o que enuncia" e "o que é enunciado". É por meio da 
verbalização e da espacialização do patológico que surge o olhar do medico.

O nascimento da clínica deve ser descrito como um fato histórico identificado com o sistema dessas reorganizações (FOUCAULT, 1980, p. XVII). Ele não só reconfigura em profundidade os conhecimentos médicos como também possibilita a criação de um discurso sobre as doenças. A questão das modificações do espaço hospitalar, o estatuto do doente na sociedade e o estabelecimento da associação entre assistência-experiência e socorro-saber também são mencionadas como eventos associados ao processo de construção da clínica. Para que tal modificação vigorasse, foi necessário situar o doente em um espaço homogêneo e coletivo - o hospital - e ainda foi preciso elaborar uma linguagem específica e um discurso científico.

O hospital deixa de ser somente uma estrutura arquitetônica para ser reconhecido como um fato médico-hospitalar. Ele passa a ser considerado uma máquina de curar onde o doente começa a ser inserido para tratamento médico. Essa inserção, segundo o autor, se deve a diversos fatores ocorridos na época, como a valoração dos indivíduos, os aspectos políticos e econômicos, o desenvolvimento da arte do corpo humano por meio da observação dos gestos, da otimização e do controle. No hospital, a introdução desses mecanismos de controle representou a disciplinarização do espaço hospitalar e a instauração do poder disciplinar confiado ao médico.

Ainda no plano da atividade médica desse período, sua construção estava atrelada a um grande modelo de inteligibilidade botânica (divisão das espécies de doença) e as doenças eram entendidas como fenômenos naturais, devido à ação particular do meio sobre o indivíduo. $\mathrm{O}$ médico torna-se uma figura de prestígio, pois detém técnicas de identificação do doente e lhe é dado o poder de decisão sobre a vida e de intervenção no corpo dos sujeitos.

Essa genealogia do poder e do saber médico desemboca no início do século XX com o chamado "Império dos médicos", ou melhor, o domínio do médico sobre o campo da saúde. Esse personagem passa a ser o único com o direito de praticar a medicina, sendo seu representante legal. As diferenças entre os saberes e as competências especializadas podem, assim, se transformar em distanciamento e em dominação sobre as pessoas. Inicia-se, então, o processo de medicalização da sociedade que "[...] traduz o fato de que o 'modelo médico', fortemente marcado pelos conhecimentos psicológicos, impôs-se na definição e no tratamento de numerosos problemas públicos contemporâneos" (HERZLICH; ADAM, 2001, p. 45). 
Assim, o que antes era considerado um problema comum entre os indivíduos (a disfunção erétil, a andropausa, a hiperatividade em crianças, as disfunções mentais, entre outros) passa a ser visto como algo que necessita de intervenção médica (CONRAD, 2007).

Após a Segunda Guerra Mundial, algumas pesquisas médicas começaram a traçar o perfil epidemiológico das doenças a partir da associação causal entre alimentação, doenças crônicas (doenças cardiovasculares, câncer, diabetes etc.), sedentarismo e fatores desenvolvidos pelo meio urbano. A ideia de que "o que é gostoso de se comer pode ser perigoso para saúde" ganha destaque (GARCIA, 1997).

A perspectiva lipofóbica (de horror à gordura) de nossa época caminha paralelamente com as mudanças no comportamento alimentar dos indivíduos, com o consumo em massa de produtos industrializados e as constantes refeições nos fast foods. Há duas décadas, essa perspectiva começou a ganhar novos contornos por meio do desenvolvimento dos estudos sobre a obesidade, que também acompanhou o crescimento das cirurgias bariátricas e os relatos de mortes atribuídas ao excesso de peso (CONRAD, 2007).

Nas sociedades ocidentais contemporâneas, as autoridades em saúde pública enfatizam que para ser saudável, é necessário ser magro e controlar o peso (DAVIES, 1999; CONRAD, 2007). Tal concepção incorpora uma dimensão institucional de estratégias de controle social e de regulação dos corpos, que passam a ser categorizados por meio de mensurações que estabelecem os graus de normalidade de peso - por exemplo, o índice de massa corporal (IMC) ${ }^{5}$. Os termos epidemiológicos ("fatores de risco", "prevalência" etc.) aliados às análises estatísticas também são responsáveis pela divulgação e disseminação das noções acerca do excesso de peso, atuando na construção da noção de responsabilidade individual (FOUCAULT, 2004; DAVIES, 1999).

Ao relacionarmos os transtornos alimentares ao processo de medicalização do comportamento alimentar, percebemos que ambos estão imersos em valores a respeito da comida, da aparência física e da relação entre saúde e doença. A anorexia nervosa, por exemplo, seria entendida como um modo de disciplinamento do corpo que interliga a dietética, a moral e o ascetismo ao tabu em torno do açúcar, da gordura ou das taxas de colesterol (FOUCAULT, 2004; ORTEGA, 2003). O sobrepeso, por sua vez, é descrito como sinônimo da falta de

\footnotetext{
${ }^{5} \mathrm{O}$ índice de massa corporal é uma medida internacional preditora de obesidade por meio da divisão entre massa corporal (peso) e altura ao quadrado.
} 
controle, da indisciplina, do desvio, do perigo e do "que não é saudável" (DAVIES, 1999).

Por meio da categoria dos transtornos alimentares, podemos observar a tensão existente entre magreza e gordura e entre aspectos simbólicos atrelados ao corpo, à comida e ao comportamento dos indivíduos que correspondem aos anseios e perigos de nossa cultura (DOUGLAS, 1976). Há também uma tensão no que diz respeito à esfera subjetiva e às expectativas sociais, visto que os casos de transtornos alimentares refletem as dores e o sofrimento dos indivíduos, pelo medo da rejeição, em uma busca autodestrutiva por adequação às normas (MISKOLCI, 2006).

\section{Quando a ingestão de comida se torna um problema médico}

Segundo o discurso biomédico, o transtorno de compulsão alimentar periódica (TCAP) é a versão em português para o binge eating disorder, nomenclatura diagnóstica de transtorno alimentar sugerida pelos manuais de doenças mentais, como o atual DSM-V (Manual Diagnóstico e Estatístico de Transtornos Mentais, tradução para Diagnostic and Statistical Manual of Mental Disorders, V Edition). Binge é um termo de origem inglesa que se refere à ideia de farra alcóolica e orgia. Quando foi transposto para o campo alimentar, binge eating passou a significar episódios de descontrole alimentar, acompanhados de sentimentos de culpa e autorreprovação (SILVA, 2005).

A primeira descrição formal de episódios de compulsão alimentar foi realizada por Stunkard em um grupo de obesos, no ano de 1959. Esse relato médico sugeriu a existência de um subgrupo com padrão alimentar diferenciado do que era visto em outros grupos de obesos. Nas últimas décadas, entretanto, essa questão ressurge como uma tentativa de diferenciação categórica entre os comedores compulsivos, os obesos sem compulsão e os bulímicos ${ }^{6}$ com seus comportamentos compensatórios de controle do peso (SILVA, 2005). Apenas com a

\footnotetext{
${ }^{6}$ A bulimia nervosa deriva do grego bous (boi) e lismos (fome), significando uma espécie de fome raivosa ou um apetite tão grande que seria possível uma pessoa comer um boi (ABUCHAIM, 1998; CORDÁS; CLAUDINO, 2002). Existem outras variantes dessa terminologia, como do latim bulismus e bolismos ou do francês bolisme. A bulimia é tipicamente caracterizada pelos episódios de ingestão compulsiva e rápida de grande quantidade de comida, alternados com comportamentos compensatórios para evitar o ganho de peso, como a indução de vômito, exercícios físicos vigorosos, o abuso de laxantes e diuréticos e a restrição severa da alimentação por um certo medo mórbido de engordar.
} 
publicação do DSM-V (2013), o comportamento compulsivo com relação à comida deixa de ser uma síndrome, muitas vezes categorizada como "não especifica", para compor o quadro dos transtornos alimentares ao lado da anorexia e da bulimia.

A compulsão alimentar possui uma relação estreita com a obesidade, porém os episódios de ingestão de alta quantidade calórica podem ocorrer em indivíduos não obesos. Decorre, assim, a noção de que a obesidade não pode ser considerada um critério de diagnóstico para o transtorno de compulsão alimentar periódica.

Em relação à bulimia nervosa, os episódios de compulsão alimentar são, contudo, aliados às técnicas de controle do peso (purgativas ou de "não engorda"). Os bulímicos, ademais, apresentam maior dificuldade em mencionar seu comportamento alimentar que os comedores compulsivos.

Outras características da compulsão alimentar são os sentimentos de angústia, autorreprovação, de tristeza, de culpa, de medo, de solidão, de descontrole, de baixa autoestima etc. Em alguns casos, o comportamento compulsivo é descrito como uma "força externa" que domina o sujeito que não consegue controlar seu comportamento alimentar - por exemplo, a existência de dispositivos gatilho que desencadeiam o processo de compulsão a partir de uma situação cotidiana específica (entrevistas de emprego, brigas, apresentações em público, entre outras) ou do contato com determinados alimentos (doces, salgados, refrigerantes etc.). Em outras situações, a compulsividade é vista como um traço da personalidade, sendo, portanto, uma predisposição psíquica do sujeito, atuando como uma "força interna" que desencadeia o comportamento compulsivo, como a depressão (ESPÍNDOLA; BLAY, 2006).

Para Espíndola e Blay (2006), as pessoas que desenvolvem esse tipo de transtorno alimentar têm relações interpessoais distantes e superficiais, marcadas por sentimentos de desconforto, culpa, vergonha e rejeição, atribuídas à má forma física. As relações familiares também são comprometidas, no sentido de que há um aumento das discussões e, por consequência, o estreitamento do diálogo. A preocupação excessiva e a dificuldade em atender às expectativas familiares emergem como elementos estressores.

Alguns estudos, segundo os autores, apontam que os indivíduos que desenvolvem a compulsão pela comida possuem histórico de experiências seja de sobrepeso/obesidade, de vivências traumáticas (de perdas, de separações etc.) ou simplesmente apresentam uma estrutura de personalidade fragilizada e baixa autoestima. Os sintomas da compulsão são 
variados - por um lado, podem surgir como uma espécie de calmante ou de conforto em momentos difíceis, por outro, a comida é vista como sinônimo de compensação ou de satisfação de outras necessidades que não necessariamente estão atreladas à fome fisiológica (ESPÍNDOLA; BLAY, 2006).

Os transtornos alimentares, como podemos observar pelo histórico da compulsão por alimento, são denominações que, mesmo com o estabelecimento de critérios de diagnóstico, apresentam certa fragilidade discursiva. Tais explicações diagnósticas possuem fronteiras tênues, no que diz respeito à existência de características semelhantes para distúrbios diferentes, como na situação da bulimia nervosa; são mutáveis por conta da relação entre contextos culturais e fatores temporais; e podem se comportar de forma variada no cotidiano, ao considerarmos o modo como os sujeitos vivenciam tal estado e suas características individuais, por exemplo, de gênero, idade, orientação sexual etc. Até que ponto o diagnóstico e o tratamento médico conseguem dar conta das diferentes experiências de indivíduos considerados anoréxicos, bulímicos ou comedores compulsivos?

Uma observação qualitativa e humana sobre a autopercepção desses indivíduos seria uma ferramenta importante para o entendimento dessas experiências individuais, assim como a observação de grupos que se identificam com uma determinada categoria médica, mas atribuem outros sentidos a ela (LIRA, 2006; SOPHIA, 2009, 2011). Não por acaso, a importância do diálogo entre os campos da saúde e das Ciências Sociais.

\section{A construção do comportamento compulsive como uma "patologia" ligada aos outros "males" da modernidade}

Nesta seção discuto o comportamento compulsivo como um fenômeno contemporâneo característico das sociedades ocidentais modernas. Esse fenômeno reflete muitas das questões que foram impulsionadas pelas mudanças ocorridas a partir do século XVIII, como o desenvolvimento das grandes cidades, o fortalecimento do capitalismo, os ideais individualistas etc. A modernidade possibilitou o aparecimento de novos costumes, hábitos e estados emotivos atrelados à individualidade e ao alto grau de racionalidade metropolitana.

Abordo aqui como as concepções de alguns autores sobre a modernidade abrem espaço 
para uma análise sobre a construção da figura do compulsivo, em um sentido genérico do termo, e sua relação com outros tipos de "patologias" subjetivas ou males de nossa época. Ao fazer esse exercício, busco dialogar com o campo da Antropologia das Emoções na tentativa de debater como alguns sentimentos são produzidos socialmente e como podem influenciar significativamente as relações entre os indivíduos e os grupos sociais.

Tomo, como ponto de partida, algumas reflexões de Simmel sobre o individualismo moderno, sua ligação com o desenvolvimento das grandes cidades e o aparecimento de novos traços de personalidade. Para o autor (1998), a monetarização da vida moderna seria produto do rompimento dos laços históricos tradicionais (vínculos de sangue e de parentesco) que foram substituídos por um elemento impessoal, inodoro, prático e universal: o dinheiro. Esse objeto se transformou na mais eficaz expressão da impessoalidade, bem como a mais adequada de todas para estabelecer relações de dependência entre milhões de pessoas envolvidas neste processo.

O dinheiro surge como resultado do crescimento da economia de mercado, passando a simbolizar e corporificar o espírito da racionalidade, da calculabilidade e da impessoalidade, podendo servir como um medidor das diferenças qualitativas entre os objetos e os homens. Além disso, ele permitiu a criação de condições para a vida na cidade, não apenas no campo objetivo, mas também no subjetivo por meio do distanciamento psicológico e funcional. Isso possibilitou a libertação dos indivíduos de algumas amarras (do Estado, da Igreja, da aldeia, do grêmio, da família etc.), ampliando assim o senso de singularidade e a dependência.

$\mathrm{O}$ indivíduo metropolitano emerge como um personagem da modernidade que estaria em uma luta incessante pela preservação da autonomia e da peculiaridade de sua existência frente às superioridades da sociedade, da herança histórica, da cultura exterior e da técnica da vida (SIMMEL, 2005, p. 577). Entretanto, nas grandes cidades, esse indivíduo é exposto a estímulos nervosos intensificados em quantidade e qualidade.

A exatidão, a reação aos estímulos citadinos, a pontualidade, o predomínio do intelecto e a individualidade seriam elementos apontados por Simmel como aqueles que distinguem o homem da metrópole do homem das cidades pequenas, onde as relações baseadas na afetividade são desenvolvidas. Não por acaso, a noção de que o ritmo característico dos centros urbanos não permite nada além de relações superficiais, impessoais e racionais.

O autor fala também da atitude blasé como um tipo social que está incondicionalmente 
reservado à metrópole e que resulta da exposição aos estímulos externos excessivos. A reação adequada a esses estímulos exigiria do indivíduo um esforço além da sua capacidade psíquica:

A essência do caráter blasé é o embotamento frente à distinção das coisas; não no sentido de que elas não sejam percebidas [...], mas sim de tal modo que o significado e o valor da distinção das coisas e com isso das próprias coisas são sentidos como nulos (SIMMEL, 2005, p. 581).

Essa indiferença do indivíduo em relação aos estímulos produzidos na metrópole seria análoga ao que o dinheiro produz nas relações mediadas por ele. Simmel discute a modernidade pelas características desenvolvidas na metrópole, otimizadas pelo dinheiro e pelo(s) tipo(s) de personalidade(s) individual(s) que desembocam no individualismo.

Norbert Elias é outro autor que debate essa questão e apresenta outras consequências da modernidade, especialmente no que diz respeito ao campo dos afetos. Em $O$ processo civilizador $(1990 ; 1993)$, o autor investiga as transformações da conduta e dos sentimentos humanos que, por conta do fator mutável da história e do grau de interdependência dos sujeitos, estabelecem as condições sociais para a complexificação das redes de interação entre os indivíduos e a formulação da singularidade de certas experiências, como a experiência do sujeito metropolitano que foi descrita acima.

Sobre a esfera das mudanças de atitude em relação às funções corporais como uma das características deste processo, o autor demonstra como os sentimentos de vergonha, repugnância e medo são produzidos gradativamente pela civilização, na medida em que se referem à internalização e à compreensão das normas sociais. Esses sentimentos representam tanto a naturalização dessas normas quanto o desconforto em infringi-las - algo que evidencia o caráter relacional do indivíduo com a sociedade por mostrar que até mesmo os sentimentos tidos como elementos de ordem individual, são produzidos e só fazem sentido por meio da interação dos sujeitos na sociedade. Os sentimentos de vergonha, de repugnância e de medo devem ser observados como sinônimos de reação à infração de uma norma e/ou de censura ocasionada por um suposto olhar do outro sobre a conduta desenvolvida pelo indivíduo. Esse processo é descrito por Elias como uma passagem (mudança na configuração das redes) do "habitus" guerreiro (de explosões das pulsões afetivas, agressivas) para o "habitus" cortesão, de valores individualizados, contidos, "civilizados", que começam a vigorar de cima para baixo na estrutura social, como um fator de distinção de classe e prestígio. 
Outro estudo de Elias que se agrega à discussão proposta é $A$ solidão dos moribundos (2008), especialmente por conta da exposição do processo de subjetivação das normas sociais, exemplificado pelo homo clausus. Tal conceito emerge nessa discussão como uma representação que o sujeito moderno faz de si mesmo ao considerar sua vida como destituída de sentido. Todavia, essa perda de sentido tem um significado para além do indivíduo isolado, visto que o sentido da vida está em relação ao outro. De acordo com Elias (2008, p. 63),

o conceito de sentido não pode ser compreendido por referência a um ser humano isolado ou a um universal derivado dele. O que chamamos de "sentido" é constituído por pessoas em grupos mutuamente dependentes de uma forma ou de outra, e que podem comunicar-se entre si. O "sentido" é uma categoria social; o sujeito que lhe corresponde é uma pluralidade de pessoas interconectadas.

O homo clausus demonstra como, mesmo em sociedades altamente individualizadas, a ideia de que cada um existe somente para si mesmo, sem a interferência de outros seres humanos e de um "mundo externo", é equivocada. A visão distorcida expressa pela autonomia do indivíduo pode resultar em sentimentos de solidão e de isolamento, característicos da estrutura da personalidade de nossa época - algo que se aplica, também, aos próprios moribundos. Conforme tal noção:

O permanente autocontrole, nesse caso, está muitas vezes tão firmemente embutido nas pessoas que crescem nessas sociedades [sociedades ocidentais modernas] que é experimentado como uma muralha realmente existente, que bloqueia o afeto e outros impulsos espontâneos na direção de outras pessoas e coisas, afastando-as como consequência (ELIAS, 2008, p.66-67).

A solidão dos moribundos seria, assim, definida como o deixar de ter significado para os outros, ou melhor, o reconhecimento de que não se é importante para alguém. Tal sentimento, para Elias, perpassa a condição do moribundo e pode ser aplicado em outros casos, em que a existência de uma pessoa é destituída de significado para ela e as demais.

A exposição de alguns dos trabalhos de Elias demonstra que a relação indivíduosociedade, em vez de ser uma relação de oposição, é marcadamente caracterizada pela sua interdependência, que opera de forma não aleatória (mas não programada) e dinâmica. Dessa interação surgem diversos tipos de configurações das redes, que influenciam tanto a estrutura 
social quanto a singularidade dos indivíduos, suas funções psíquicas e os dramas individuais/sociais - a exemplo do elevado nível de individualização, ao lado dos sentimentos de solidão e isolamento, como traços da personalidade dos indivíduos das sociedades ocidentais modernas.

Sigmund Freud é outro pensador que discute a dinâmica dos indivíduos nas sociedades e como esse tipo de interação é responsável pelo desenvolvimento de diversos comportamentos e perturbações psíquicas, como a compulsão. No livro O mal-estar na civilização, Freud (1997) parte do pressuposto que a cultura cria obstáculos às pulsões destrutivas, agressivas e sexuais dos homens, ocasionando uma tensão entre os impulsos de amor e de morte. Segundo essa visão, a cultura se constitui por meio da difusão da máxima "amai ao próximo como a ti mesmo", não só como um mecanismo de proteção dos homens, mas também como fator integrativo e regulador. Ao "amar o próximo", esse homem estaria plenamente realizado ou, como nomeia o autor, estaria imerso em um "sentimento oceânico" (um sentimento de fusão), que o remete a uma situação mítica de origem da sua relação com o mundo externo.

No entanto, Freud aponta que tal sentimento é ilusório, no sentido de que essa "plenitude" e essa "fusão" estariam associadas ao período de gestação do indivíduo que é rompido após seu nascimento (situação inevitável). A partir desse momento, instaura-se no sujeito um "sentimento de desamparo" ou de "falta" que a cultura busca suprir por meio do "amar ao próximo como a ti mesmo".

$\mathrm{O}$ autor se refere ao sentimento de "mal-estar" dos indivíduos com a cultura, demonstrando o paradoxo presente nesta relação, em que a cultura é concomitantemente um artifício para proteção diante do sentimento de desamparo e a própria fonte desse sentimento. Não por acaso, o caráter fantasioso expresso na máxima que prega o amor universal.

Para fundamentar tal argumento, Freud busca demonstrar que antes do advento da cultura (uma situação hipotética), o medo da perda e o sentimento de culpa eram inexistentes, tendo em vista que não havia resistência aos impulsos, à satisfação dos prazeres nem havia uma consciência moral. Com o processo de introjeção da norma e de sanção do superego, próprios da vida em sociedade, o homem passa a sentir culpa e medo da perda. Essa característica será, aos poucos, acentuada pela relação entre o "eu" e o "outro" (pensado como objeto de desejo).

A iminência da perda do amor desse "outro" se transforma em punição do próprio "eu", ou seja, o impulso agressivo, impossibilitado de ser externalizado pelo sujeito contra aquele 
que supostamente não correspondeu às suas expectativas, volta-se para o próprio sujeito sob a forma de autopunição.

A exposição do texto de Freud aponta como os aspectos inerentes à condição humana são inibidos pela sociedade e como isso ocasiona contradições na formulação dos preceitos culturais, bem como gera uma série de conflitos no âmbito individual. A passagem do estado natural do homem para um estado cultural estaria na canalização dos impulsos sexuais para o trabalho, gerando os bens materiais e intelectuais da civilização. Essa concepção teórica seria um diagnóstico pessimista que o autor faz da modernidade, na medida em que é nesse processo que aparecem as doenças psíquicas, ou seja, uma reação individual às repressões que a sociedade faz em relação aos impulsos naturais.

A ideia de "mal-estar" proposta por Freud, segundo Souza (2012), assume novas formas na contemporaneidade, podendo ser associada às condições econômicas e sociais que os indivíduos experimentam. De acordo com essa visão:

Já não é mais de uma tensão física, sexual, que causa a ansiedade, mas é uma tensão psíquica, causada pela preocupação, pelo medo e pela insegurança causada por condições econômicas e sociais. Os estímulos externos causam todo tipo de desajuste psíquico. É comum a experiência da melancolia, da depressão, do desânimo, do desinteresse pela vida, da baixa autoestima e da sensação de inutilidade. As doenças que eram menos comuns na época de Freud se tornaram grandes problemas para psicólogos e psiquiatras, são os traumas de roubos e de sequestros, a síndrome do pânico, a compulsão de consumo, a síndrome de perseguição, a misantropia e a depressão. Todas essas doenças são acompanhadas de crises de ansiedade. São doenças típicas de nossa época e que estão associadas ao mal-estar na civilização (SOUZA, 2012, s/n).

Se, por um lado, a vida moderna é descrita pelos autores como uma época marcada pelo desenvolvimento e complexificação da esfera social, por outro, a fragmentação subjetiva do indivíduo se apresenta de forma conflituosa no que diz respeito ao seu comportamento e ao seu relacionamento com os outros. O indivíduo experimenta a solidão, o isolamento ou o desamparo.

Ao problematizar as consequências da modernidade no campo da intimidade, Anthony Giddens (1991) fala do comportamento compulsivo como sinônimo da perda da autonomia 
individual, da capacidade de escolha, do controle sobre o "eu" (GIDDENS, 1993 apud SARTI, 2002). Isso se deve ao fato de que nas sociedades tradicionais as escolhas individuais eram restritas. O indivíduo não precisava se revelar por meio de ações ou hábitos. Na modernidade, esse indivíduo desenvolve a angústia das escolhas que formarão sua identidade em meio a múltiplas alternativas de estilo de vida. É essa dificuldade individual que habita o comportamento compulsivo que, para o autor, transformou-se em característica de nossa época. Segundo Giddens (1993, p.84):

\begin{abstract}
A compulsão é uma forma de comportamento que um indivíduo acha muito difícil, ou impossível, parar apenas pelo poder da vontade, e cuja realização produz a liberação de uma tensão. [...] O comportamento compulsivo está associado a uma sensação de perda de controle sobre o eu; a pessoa pode realizar as ações rituais em uma espécie de estado de transe. Não conseguir realiza-la provoca um estado de ansiedade.
\end{abstract}

Tal comportamento, de acordo com o autor, também está atrelado ao vício como um mecanismo de conforto para o sujeito, pois é uma forma de amenizar a ansiedade. Contudo, tal experiência é mais ou menos transitória: "Todos os vícios são essencialmente narcotizantes, mas o efeito químico, se existir algum, não é um elemento essencial à experiência do vício" (GIDDENS, 1993, p. 84). O vício caracteriza-se por proporcionar êxtase e dependência como modos de "desligamento da realidade". O êxtase é entendido como uma sensação momentânea de exaltação ou euforia que, em algumas situações, leva a sensações de triunfo e relaxamento. A dependência se traduz na necessidade e no esforço do indivíduo para atingir o êxtase. O indivíduo, dependente de alguma experiência ou comportamento, busca abrandar sua ansiedade, mas, com o tempo, essa necessidade é sucedida pela depressão e sentimentos de vazio. Com o aumento da dependência tal conflito de sentimentos torna-se cíclico.

A experiência do vício, de acordo com Giddens, é um "afastamento do eu” ou um “abandono temporário da preocupação reflexiva7 com a proteção da autoidentidade". O sentimento de perda do eu é seguido pelos sentimentos de remorso, vergonha, pânico e autodestruição que irão aumentando gradativamente sua importância na vida do sujeito.

\footnotetext{
${ }^{7}$ A reflexividade é um conceito utilizado por Anthony Giddens como forma de entender a modernidade em um estágio contemporâneo que envolveria um processo de individualização e destradicionalização em seu momento mais radical. Para o autor: "A reflexividade da vida social moderna consiste no fato de que as práticas sociais são constantemente examinadas e reformuladas à luz de informação renovada sobre essas próprias práticas, alterando, assim, construtivamente seu caráter" (GIDDENS, 1991, p. 45).
} 
O viciado é alguém que possui um comportamento "imoderado", não apenas na esfera pública como também na vida subjetiva. Há, segundo o autor, a recusa ou a aversão do indivído em aceitar o próprio destino. Não por acaso, a noção de que todos os vícios são patologias da autodisciplina atua em duas direções: na liberação ou na contenção de um determinado comportamento. Conforme o autor, os transtornos alimentares exemplificam tal ideia, pois o vício pela comida se manifesta tanto nas farras alimentares dos bulímicos ou comedores compulsivos como nos períodos de jejuns anoréxicos. Tais práticas são vistas como dois lados da mesma moeda, no sentido de que podem coexistir como propensões do mesmo indivíduo.

Giddens também cita o exemplo do alcoolismo como uma doença física que relaciona o vício à escolha do estilo de vida e à autoidentidade. Para o autor, o problema teórico-analítico de alguns pesquisadores é considerar a dependência alcóolica como somente uma doença, sem atentar para as noções a respeito da mudança substantiva no estilo de vida do sujeito.

Ao mencionar o modelo terapêutico dos Alcóolicos Anônimos (AA), o autor discute formas de recuperação do vício por meio do reexame da autoidentidade em um contexto no qual não há julgamentos ou críticas sobre os atos cometidos pelos sujeitos, pois todos passam pelo mesmo dilema. Nas reuniões do AA, esses sujeitos são estimulados a falar sobre seus temores e experiências abertamente, reconstruindo, assim, outra narrativa sobre o eu.

A reelaboração do eu e seu alinhamento com as práticas do estilo de vida são fundamentais para o indivíduo que almeja a autonomia pessoal nas sociedades ocidentais contemporâneas. Entretanto, na maioria das vezes, os processos de autorrealização são parciais - por isso, a presença de tantos vícios em nossa época.

Os vícios são modos de comportamento que penetram à força no projeto reflexivo do sujeito, mas recusam-se a estar relacionados a eles. Adviria, assim, a dificuldade do indivíduo em superar o vício e a aceitação dessa noção pela literatura terapêutica. " $O$ vício é uma incapacidade de administrar o futuro, e, sendo assim, transgride uma das principais ansiedades que os individuos têm de enfrentar reflexivamente” (GIDDENS, 1993, p. 88). Todo vício representa um comportamento de defesa, de fuga, um reconhecimento de perda de autonomia que pode comprometer a competência do eu.

Nesse sentido, o comportamento compulsivo, os vícios e outros males contemporâneos são experiências subjetivas que possuem sentido dentro de um contexto sociocultural no qual o indivíduo se vê incapaz de controlar seus afetos e de lidar com as exigências e anseios da 
sociedade. A tensão existente entre os indivíduos e a coletividade também é discutida nos trabalhos sobre os processos de adoecimento, como o de Fainzang (2003), de duas maneiras: de um lado, por um discurso nativo que enfatiza a atribuição das causas à sociedade e aos "modos de vida" que são impostos por ela; e, de outro lado, temos a posição pautada nos processos de busca individual de um responsável (autoacusação, acusação de um familiar, acusação de um outro distante ou estranho, acusação da sociedade etc.) no desenvolvimento de determinada doença ou mal. Considero aqui que as experiências subjetivas, especialmente a compulsividade por comida, não estão limitadas a uma ou a outra explicação e sim oscilam entre essas duas formas de entendimento.

\section{Conclusão}

A temática das emoções acompanha o desenvolvimento das Ciências Sociais como campo disciplinar, principalmente a Antropologia. Presentes em alguns trabalhos clássicos ${ }^{8}$, os afetos são abordados de forma secundária e não como um objeto de estudo autônomo ${ }^{9}$. As emoções eram vistas como "naturais", dadas a priori, e também como fenômenos subjetivos, individuais e particulares que são regulados pela sociedade. Por meio dos estudos de Durkheim e de Simmel ${ }^{10}$ que a noção de produção social dos sentimentos começa a ganhar destaque.

De lá para cá, a Antropologia das Emoções emerge como um campo analítico, agregando diferentes propostas teórico-metodológicas para o entendimento e a comparação das dinâmicas emocionais que operam em determinados contextos sociais e culturais. Para Rezende e Coelho (2010, p. 15):

A preocupação dessa abordagem contextualista [...] é dupla: mostrar como o próprio significado das emoções varia dentro de um mesmo grupo social dependendo das circunstâncias em que se manifestam, e atentar para as consequências da expressão dos sentimentos nas relações sociais e de poder.

\footnotetext{
${ }^{8}$ As emoções aparecem, tanto na Sociologia clássica, com Émile Durkheim e Georg Simmel, como também na Antropologia, com os trabalhos de A R Radcliffe-Brown, Ruth Benedict, Marcel Mauss, entre outros.

${ }^{9}$ Nesta época, cabia à Psicologia a elaboração desses estudos.

${ }^{10}$ Embora ambos tenham descrito os sentimentos como estados subjetivos e não sociais. Por caminhos diferentes, buscam explicar a existência de emoções produzidas socialmente que podem trazer impactos para as relações dos indivíduos e a sociedade (REZENDE; COELHO, 2010).
} 
Com base nessas reflexões, este artigo buscou analisar o modo como as emoções conflituosas e dolorosas, características da compulsão por comida, podem ser consideradas experiências coletivas que não desqualificam a experiência individual. Isso significa que, ao sentir ou comunicar determinada dor (seja corporalmente ou pela fala), o sujeito se manifesta por meio de uma gramática emocional que é orientada por um sistema de classificação psicológica e de expressão corporal que só faz sentido se contextualizada. Não por acaso, a alusão de alguns fenômenos sociais (como a moda, o consumismo, o poder biomédico, entre outros) para compreendermos os aspectos envolvidos na relação entre a compulsão alimentar e seus interlocutors. Esse exercício possibilita a inclusão de outros olhares, discursos e experiências acerca desse transtorno alimentar cujas explicações não se restrigem a um ou a outro saber e que podem, de algum modo, propor novas formas de entendimento e de lidar com esse sofrimento.

\section{Referências Bibliográficas}

ABUCHAIM, Ana Luiza Galvão. Aspectos históricos da anorexia nervosa e da bulimia nervosa. In: ABUCHAIM, Ana Luiza Galvão et al. Transtornos Alimentares e Obesidade. Porto Alegre: ArtMed, 1998. p. 13-20.

BAUMAN, Zygmunt. Vida para o consumo: a transformação das pessoas em mercadoria. Rio de Janeiro: Zahar, 2008.

CLAUDINO, AM.; BORGES, MB. Critérios de diagnósticos para os transtornos alimentares: conceitos em evolução. Revista Brasileira de Psiquiatria, São Paulo, v. 24, p.0712, 2002. Suplemento III.

COELHO, R; SEVERIANO, MF. Histórias dos usos, desusos e usura dos corpos no capitalismo. Revista do Departamento de Psicologia da Universidade Federal Fluminense, Rio de Janeiro, v.19, n.1, p. 83-100, 2007.

CONRAD, Peter. The medicalization of society: on the transformation of human conditions into treatable disorders. Baltimore: Johns Hopkins University Press, 2007.

CORDÁS, TA; CLAUDINO, AM. Transtornos alimentares: fundamentos históricos. Revista Brasileira de Psiquiatria, São Paulo, v. 24, p. 03-06, 2002. Suplemento III.

DAVIES, Deirdre. Health and the discourse of weight control. In: PETERSEN, Alan; 
WADDELL, Charles. Health Matters: A sociology of illness, prevention and care. Buckingham: Open University Press, 1999.

DOUGLAS, Mary. Pureza e perigo. São Paulo: Perspectiva, 1976.

ELIAS, Norbert. A solidão dos moribundos. Rio de Janeiro: Zahar, 2008.

O processo civilizador I: uma história dos costumes. Rio de Janeiro: Zahar, 1990. 1993.

O processo civilizador II: formação do estado e civilização. Rio de Janeiro: Zahar,

ESPÍNDOLA, CR; BLAY, SL. Bulimia e transtorno da compulsão alimentar periódica: revisão sistemática e metassíntese. Revista de Psiquiatria do Rio Grande do Sul, Porto Alegre, v. 28 , n. 3, p. 265-275, 2006.

FAINZANG, S. Entre as práticas e recursos terapêuticos: as problemáticas de um itinerário de pesquisa. Antropolítica, Niterói, n. 15, p. 19-38, 2003.

FOUCAULT, Michel. O nascimento da clínica. Rio de Janeiro: Forense-Universitária, 1980.

Microfísica do poder. Rio de Janeiro: Graal, 1996.

Vigiar e punir: nascimento da prisão. Petropolis: Vozes, 2004.

FREUD, Sigmund. O mal-estar na civilização. Rio de Janeiro: Imago, 1997.

GARCIA, RW. Representações sociais da alimentação e saúde e suas repercussões no comportamento alimentar. Physis: Revista de Saúde Coletiva, Rio de Janeiro, v. 7, n. 2, p.51$68,1997$.

GIDDENS, Anthony. As consequências da modernidade. São Paulo: Ed. Unesp, 1991.

A transformação da identidade: sexualidade, amor e erotismo nas sociedades modernas. São Paulo, Editora da Unesp. 1993.

HERZLICH, Claudine; ADAM, Philippe. Sociologia da doença e da Medicina. Bauru, São Paulo: EDUSC, 2001.

HOCHSCHILD, Arlie Russell. Trabalho emocional, regras de sentimento e estrutura social. In: COELHO, Maria Claudia (Org.). Estudos sobre interação: textos escolhidos. Rio de Janeiro: EdUERJ, 2013, p. 169-209.

LIRA, LC de. Narrativas de Ana: corpo, consumo e self em um grupo pró-anorexia na internet. Dissertação de Mestrado em Antropologia, UFPE, Pernambuco, 2006.

MINTZ, SM. Comida e antropologia: uma breve revisão. Revista Brasileira de Ciências 
Sociais, São Paulo, v.16, n. 47, p. 31-41, 2001.

MISKOLCI, R. Corpos elétricos: do assujeitamento do sujeito à estética da existência. Estudos Feministas, Florianópolis, v. 14, n.3, p. 681-693, 2006.

ORTEGA, F. Práticas de ascese corporal e constituição de bioidentidades. Cadernos de Saúde Coletiva, Rio de Janeiro, v. 11, n.1, p. 59-77, 2003.

PROSE, Francine. Gula. São Paulo: Arx, 2004.

REZENDE, Claudia B.; COELHO, Maria Claudia. Antropologia das Emoções. Rio de Janeiro, Editora FGV, 2010.

SACCOL, AP. A representação social da anorexia nervosa entre profissionais do sistema único de saúde do município de Florianópolis/SC: um estudo de caso. Dissertação de Mestrado em Sociologia Política, UFSC, Santa Catarina, 2009.

SARTI, Cynthia. Família e individualidade: um problema moderno? In: CARVALHO, Maria do Carmo Brant de (Org.). A família contemporânea em debate. São Paulo: EDUC e Cortez, 2002, p. 39-49.

SILVA, Ana Beatriz B. Mentes insaciáveis - anorexia, bulimia e compulsão alimentar. Rio de Janeiro: Ediouro, 2005.

SIMMEL, Georg. As grandes cidades e a vida do espírito. Mana, v.11, n.2, p.577-591, 2005.

Da psicologia da moda: um estudo sociológico. In: SOUZA, Jessé; ÖELZE, Berthold. (Org.). Simmel e a modernidade. Brasília: UNB, 1998, p. 159-165.

Fashion. In: LEVINE, Donald N. Georg Simmel on individuality and social forms: selected writings. Chicago and London: University of Chicago press, 1971, p. 294-323.

. "O dinheiro na moderna cultura." In: SOUZA, Jessé; ÖELZE, Berthold. (Org.). Simmel e a modernidade. Brasília: UNB, 1998, p. 23-40.

Sociologia da refeição. Estudos Históricos, Rio de Janeiro, n.33, p. 159-166, 2004.

Disponível em: http://bibliotecadigital.fgv.br/ojs/index.php/reh/article/viewArticle/2218 (Acesso em março de 2014).

SOPHIA, BV. O movimento pró-anorexia e pró-bulimia na Internet: uma reflexão sobre as práticas alimentares, saúde e doença, corpo e identidade. Monografia de Graduação em Ciências Sociais, UERJ, Rio de Janeiro, 2009.

Quando a magreza torna-se um ideal masculino: um estudo socioantropológico sobre a anorexia e a bulimia em homens. Dissertação de Mestrado em Ciências Sociais, UERJ, Rio de Janeiro, 2011. 
SOUZA, MA. O mal-estar na civilização moderna. O viés, 2012.

Disponível em: http://www.revistaovies.com/artigos/2012/07/o-mal-estar-na-civilizacaomoderna/ (Acesso em: Julho de 2012).

SUDO, N. Diga-me quanto pesas e te direi quanto vales: um estudo sobre a representação do gordo em revistas contemporâneas. Dissertação de Mestrado em Saúde Coletiva Política, Planejamento e Administração, IMS/UERJ, Rio de Janeiro, 2004. 